\title{
Alfred Ackermann-Teubner-Gedächtnispreis zur Förderung der mathematischen Wissenschaften.
}

Der von Herrn Domberm Dr. Dr. Ing. Alfred Ackermann-Teu bner in Leipzig im Jahre 1912 der Universität Leipzig gestiftete "Alfred-AckermannTeubner Gedächtnispreis zur Förderung der Mathematischen Wissenschaften" in Höhe von RM 500,- ist für das Jahr 1934 durch das Preisgericht dem Professor an der Technischen Hochschule in Dresden Dr. E. Trefftz für seine Arbeiten zur angewandten Mechanik zuerkannt worden. 